\title{
Hair Dressing Entrepreneurs' Motivation, Personality and Business Performance Research
}

\author{
Wu Lijun ${ }^{1}$, Wu Tien Chieh $^{1}$, Duan Wanchun ${ }^{1}$ Yang Hongjuan ${ }^{1} \&$ Liao Sengui ${ }^{2}$ \\ ${ }^{1}$ Management and Economy School, Kunming University of Science and Technology, China \\ ${ }^{2}$ Management and Economy School, National Taibei University of Technology, Taibei, Taiwan, China \\ Correspondence: Wu Lijun, Management and Economy School, Kunming University of Science and Technology, \\ China. E-mail: wu0933155@yaoo.com.tw
}

Received: March 14, 2014

doi:10.5539/ijbm.v9n7p126
Accepted: April 10, 2014

Online Published: June 22, 2014

URL: http://dx.doi.org/10.5539/ijbm.v9n7p126

\begin{abstract}
Our country economic development as affected by globalization, gradually rendering service economy (Chen, Lijing, 2000), this study targeted the internal entrepreneurs of hairdressing chain to explore the relationships between their personality and performance. Otherwise, the study accounted the entrepreneur's motivation as the control variable, to examine how the variables of personality, entrepreneur's motivation, and business performance are related. The study uses questionnaires survey as main method, and retrieved sample size of 150 valid questionnaires were conducted compiling information for analysis by using spss 12.0 statistical software. The results firstly shows that the more personality of extraversion and friendly entrepreneurs have, the better business performance will be. Then, achievement-money of entrepreneurial achievement motivation affects business performance significantly. Finally, the mutual affect of extraversion-friendly, and achievement-money has a positive significant effect on Business Performance.
\end{abstract}

Keywords: business performance, agreeableness extrovert, wealth achievement

\section{Introduction}

\subsection{Motivation}

Chen Lijing (2000) explained that the service economy refers to a country's GDP or the number of employees is bigger than the country's GDP, or more than half of the total number of employees, and when the service industry has a significant effect on the country's economic activity, which means the country's economy has developed to service economy. Recent years, Taiwan's economic development has been matured, and the service industry plays more important role in this stage of development.

Hairdressing Services is a popular industry, also a human and technology-intensive fashion industry, while the core of hairdressing services business is the technical staff. Facing an increasingly competitive environment, lifelong plans for staff career should be the key to keep business continue and make big progress.

The article of economists Macramé (1976) published in London 'Economist' said, 'The successful large companies should transform into confederations of entrepreneur' This is the original idea of confederations of entrepreneur, which inspired the scholar Macramé Pinchott to commit to research this particular concept and implement it with efforts (Pinchott, 1988) .

Performance is an important indicator of business activity (Venkatraman \& Ramanujam, 1986), only through the relevant performance measurement, the owner knows better about the performance of corporate strategy before implementation. What is the best method of performance measurement has not been determined, this study used the following three different metrics to measure as following, financial performance, business performance, and organization performance. (1) Financial performance is the accounting-related manner (such as ROA, ROS, ROE , etc. ), and more used to measure the current profitability. (2) Business performance is the market-related performance measures (such as market share, sales growth, diversification, product development, etc.), not only to measure current market but also the company's position in future competitions. (3) Organizational performance is the way to measure employees' performance (such as employee satisfaction, quality, social responsibility, etc.) to measure the quality and their social reaction . 
However, the Five Factors Model (FFM) derived from the argument of Fiske (1949) Norman (1963) and Tuppes \& Christal (1961) and others. Digman (1990) made the five model manipulation more stable. McCrae \& Costa (1990) inferred the foundation of the five personalities based on the measure tools, observers pattern, both convergent and discriminate validity (John, 1990). Digman and Takemoto-Chock (1981), Costa \& McCrae (1986) and Peabody \& Coldberg (1989) divided the "Big-Five" into five categories. Through these literature data, the personality affects the performance in hairdressing service business, therefore, the first motivation of this study is to investigate whether the personality of the hairdressing industry internal entrepreneur affect their business performance?

For hairdressing industry, the desire to achieve personal wealth has been considered as the most important motivation. But is it true? The findings of Amit, MacCrimmon, Zietsma, \& Oesch (2001) findings said, for entrepreneurs, wealth is not the only motivation for achievement, nor the most important for starting an adventurous career. Other motives, such as innovation, vision, independence and challenges have become more important and significant. Also in the findings of Dubini (1989) who investigated 163 entrepreneurs, and he strengthened the theoretical basis of this topic by factor analysis empirical research. Therefore, the second motivation of this study is to explore the motivation of the hairdressing industry internal entrepreneur affects their business performance?

Entrepreneurship is not a natural action, it is a mix of the social recognition and influence. Different entrepreneurs' personality and different motivations may have different impacts on their business performance. Therefore, the third motive is to investigate whether the motivation of the hairdressing industry internal entrepreneur affects the effect of their personality on their business performance?

\subsection{Research Purpose}

The concept of entrepreneurship originated from 1976, while it was widely discussed by the community after 1985, especially by the scholar Pinchott, who mentioned and completed in his book, after that the relevant books appears one after another. This study is about to explore the relevance of entrepreneurs' personality, motivation and business performance in the internal entrepreneurship of the hairdressing chain industry, which can provide a reference to the current hairdressing owners in their choice of expanding their business, or solving the lost of talents. Based on the above, the study is scheduled to collect information through a questionnaire and then solve the following problems after the statistical analysis.

H1: hairdressing internal entrepreneur's personality has a positive impact on business performance.

H2: hairdressing internal entrepreneur's motivation has a positive impact on business performance.

H3: hairdressing internal entrepreneur's motivation has a impact on the effect of the entrepreneur's personality on business performance, which means the interaction effect of the entrepreneur's personality and motivation has an effect on their business performance.

\section{Literature Review}

\subsection{The Definition of Internal Entrepreneurship}

Entrepreneurship refers to shop chain stores established by the company and the employees, both the company and employees have a portion of the store ownership and management control, generally known as (semi outlets). Business model is as follow: (1) each branch is a joint venture, both the headquarter and the best performing employees. (2) The relationship between the company and the manager is built on mutual understanding and trust. (3) The rights and obligations in the entrepreneurial shops are similar to the ones in franchise. (4) The costs and profits of entrepreneurship shop are distributed by headquarter and the manager in accordance with the proportion of their share.

The purposes of establishing entrepreneurship are (1) to motivate employees and help employees to identify the value of company (2) to strengthen the headquarter, and also take over the market meanwhile to maximize the profits through the outlets. In the current domestic franchise system, some are outlets, some are franchisee, but most are mixed, that is, the company also has sales stores and franchise stores.

In 1976, the article of economists Macramé published in London "Economist" mentioned the successful large companies should transform into "confederations of entrepreneur", which is the original idea of confederations of entrepreneur. This concept inspired the scholar Macramé Pinchott to commit to research this particular concept and implement it with efforts (Pinchott, 1988). At present, most of the foreign literature are about internal entrepreneurship explored the e high-tech companies such as 3M, IBM and other companies, which is designed to inspire the employees to engage in innovation and research and development activities, so either the motivation or other aspects cannot be applied, therefore, this section describes only the internal business definitions and explains the benefits of the chain's internal business. 
Cooperation and voluntary franchising is the deformation of franchise chain, the main differences lie in the rights and obligations stipulated in the content, in fact, there is no such classification in the United States. The classification is derived as chains in Japan, so in this study on the sub hold those to chain founding countries-the classification of the United States is as the standard, including the chain patterns of direct management and franchise, plus Taiwan's unique internal entrepreneurial types are classified as Figure 1.

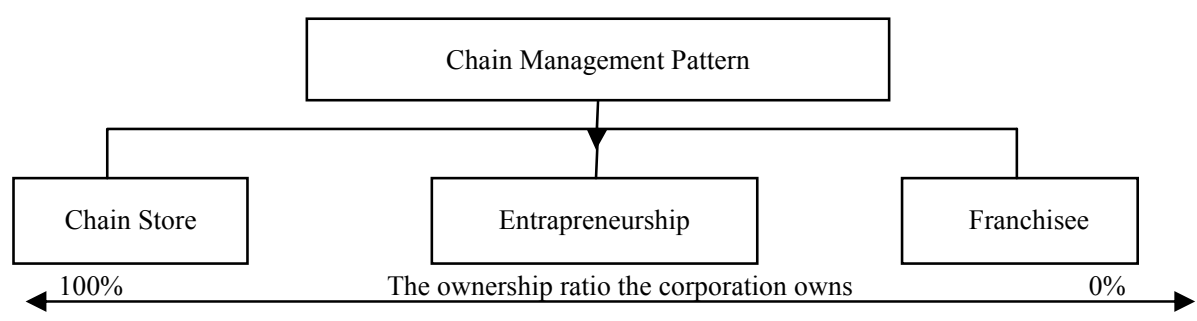

Figure 1. Chain pattern classification

\subsection{Entrepreneur's Personality}

Personality is used to indicate the personal thoughts, feelings and behavior patterns, making the individual with special qualities different from others in a considerable time and in a consistent manner. Personality is a psychological phenomenon, in general the personality of some people shows apparently, while some are not revealed, but kept deeply inside. Therefore, it is a stable personality characteristic which differs from the pattern of others, showing a certain tendency, it represents a real individual from the inside to outside. Also the formation of personality is the accumulation of a series of psychological growth and development, because of its continuity and stability, and also the individual difference, the personality difference can be used as a standard to distinguish individual difference. In other words, since personality can show the feature of individual's different behavior, therefore individuals with different personality type will have different behaviors (Zhang Run Book, 1973).

As the meaning of personality is broad and complex, scholars have an argument about the definition and criteria of personality. Allport (1963) thinks that the personality is an inherent tendency of the individual's response to the stimuli from the environment, and this tendency is affected by both the heritage and environment. Zhangchun Xing (1997) thinks that the personality trait is the unique character of individual adapt to the transaction and the whole environment. Generally, the definition of personality trait more frequently used in psychology is as following, the individual's behavior, unique individual responses that show personality characteristics (eg., shyness, timid, etc.), if these features consistently appear in many different contexts, we call them personality (Costa \& McCrae, 1992).

\subsection{Five Personality Model Theory}

Five personality model (Five Factors Model, FFM) is originally from Fiske (1949) Norman (1963) and Tuppes \& Christal (1961) and so on. Digman (1990) made the five model manipulation more stable. McCrae \& Costa (1990) pointed out that this five factors through measure tools, observers pattern, and discriminate validity. In 1960s and 1970s, the importance of the five factors personality has not been discovered. Until the 1980s, according to the samples of children, student, adult, female, male, British, Dutch, Germans, and the Japanese, many scholars inferred that the five personality are the basis (John, 1990). Digman and Takemoto-Chock (1981), Costa \& McCrae (1986) and Peabody \& Coldberg (1989) divided the "Big-Five" into five categories.

\subsubsection{Emotional Stability}

The first scale on the nervous established during World War I, and appeared in the Woodworth's (1919) data form, was used to assess the ability of soldiers under military pressure. The individual with emotional stability more easily tends to experience negative attitudes than other individuals (Judge, Heller \& Mount, 2002) This type of person is very sensitive to the ridicule of others, and tends to have low self-esteem, if there are such people in the community, comparing with other people, they will make you feel uncomfortable, such people are less able to stand the pressure, and easily feel lonely, helpless and panic (Lilian HSU, 2002).

\subsubsection{Extraversion or Surgency}

Extraversion or surgency is the comfortable level individual feels, people with higher extraversion level are more 
gregarious and sociable, and they are more confident, initiative, active and lovely, they like the performance and love to make friends and so on; people with low extraversion are more conservative, shy and quiet. About the definition of extroversion and introversion, Jung (1917) divided them into four dimensions. Firstly, on the way of thinking. The extravert try to understand the point of the outside world will perspectives; introvert try to explain their point of view. Secondly, on sensory aspects. The extravert is more sociable; introvert is more inclined to think rationally. Thirdly, on perceptual aspects. The extravert is more practical and are interested in the outside world. Fourthly, on intuition aspects. The extravert is more creative and likely to look for new opportunities in the outside world; introvert is relatively impractical and likely to look for new opportunities in themselves.

\subsubsection{Openness or Experience}

People with high level of openness and spirit experience more deeply and are more sensitive, they are more likely to accept new things, like the innovative ideas, have curiosity and imagination, like freshness, diversity preferences will change over time (Yating $\mathrm{Xu}, 2002$ ). They are more creative, have more innovative ideas, like thinking and innovative ideas, and focus on inner feeling, experience deeper (McCrae \& John, 1992); people with low level of openness are more conservative and content with low-status quo.

\subsubsection{Agreeableness}

Friendly people are easy to get along with others, to get along in a group, do not attack others, mostly in the role of submission, relatively easy to establish friendly relations with others (Digman \& Inouye, 1986), they believe that people are good, well-intentioned; people with low friendliness are manifested relatively indifferent, easily to show their emotions, they are more likely to show aggressive behavior and language, they are not in the submissive roles, and are less likely to establish friendship with others.

\subsubsection{Conscientiousness or Dependability}

This means that the drives to complete something, including the following features: being organized, systematic, efficient, practicality and persistent (Coldberg, 1992). People with completeness are more serious and responsible reliable, hard work, achievement oriented, and persistent; people with low completeness are easily tired and upset, less organized and insecure.

This study refers to Qiu Ming's thesis (2008), using the Big Five (emotional stability, extraversion, agreeableness, openness to learn, rigor) architecture of McCrae and John (1992), and the one of Schmit et al. (2000) formulate the personality inventory table according to the assessment of five personality.

\subsection{Entrepreneur's Motivation Theory}

To entrepreneurs, the desire to achieve personal wealth had been considered as the most important motivation. But is it true? The findings of Amit, Mac Crimmon, Zietsma, \& Oesch (2001) showed, to entrepreneurs, wealth is not the only motivation for achievement, nor the most important for starting an adventurous career. Other motives, such as innovation, vision, independence and challenges have become more important. Future research should focus less on the Wealth achievement and more attention to other motives. Various characteristics decision mode patterns can completely explain why this challenging decision was made. Also Dubini (1989) used factor analysis to analyze the questionnaires from 163 entrepreneurs, its empirical results is the theoretical basis of this research, so Dubini's seven motivational factors are used as the variables in this essay to study the entrepreneurial motivation, including achievement, welfare, status, money, escape, freedom and rolemodels.

\subsection{The Business Performance}

There are many metrics of operating performance among past studies, but the best method of performance measurement has not been determined. In this essay, the study of Venkatraman \& Ramanujam in 1986 will be used as an example, and three different variables will be used to discuss the performance; which are Financial, Business), and Organization.

First, financial performance is the accounting-related manner, such as ROA, ROS, ROE, etc., and more used to measure the current profitability. Second, business performance is the market-related performance measures, such as market share, sales growth, diversification, product development, etc., which is not only used to measure market also predict the company's future competitive position. Third, organizational performance is measured by performance related to the employees, such as employees' satisfaction, quality, social responsibility, etc., which is more used to measure the quality of social reaction. In this study, Financial, business, and organization are the three dimensions of performance metrics.

\subsection{The Relevance between Entrepreneurial Personality and Business Performance}

In the study of Lee \& Tsang (2001) about the impact of personality emerging entrepreneurship, background and 
network behavior on performance, the results showed that experience, network activity, working partners, internal locus control and achievement motivation have a positive impact on the company's growth, which confirms the personality trait has a significant effect on the business performance.

In the study of Luozong Min, Wang Man and Xu Xiongjie (2008), they investigated the effect of entrepreneur's personality on business performance, the result showed that various dimensions of personality have a positive impact on business performance. The entrepreneur who is more extravert, stable in emotion, compatible, conscientious and open will be better in the business performance. Based on the previous discussion, we propose the first hypothesis.

H1: hairdressing internal entrepreneur personality have a positive impact on Business Performance.

\subsection{The Relevance between Entrepreneur's Motivation and Business Performance}

About the relevance between entrepreneur's motivation and business performance, the research of Ghosh \& Kwan (1996) indicates different entrepreneur's motivation could have different impacts. Collins et al. (2004) used the meta-analysis method to analyze entrepreneurial achievement motivation and entrepreneurial behavior, the result confirmed that motivation affects entrepreneurial career and their business performance. Huang Baodong (2006) studied the relevance among Taiwan SME business personality, entrepreneur's motivation, entrepreneurial strategy and business performance, the results showed that entrepreneur entrepreneur's motivation has a significant effect on Business Performance. Based on the previous discussion, this study proposes the second hypothesis.

$\mathrm{H} 2$ : hairdressing internal entrepreneur motivation has a positive impact on business performance.

\subsection{The Relevance of Personality, Entrepreneur's Motivation, and Business Performance}

When entrepreneurs starts business based on positive entrepreneur's motivation, such as their expectations and beliefs engaged in entrepreneurship, because this type of motivation of entrepreneurs is to achieve their aspirations and ideals, they have a higher level of tolerance for frustration, in this context, that may have positive and significant effect on the non-economic achievement of entrepreneurs (Hsu Tung Chan, 2008). Huang Baodong (2006) studied the relations of Taiwan SME business personality, entrepreneur's motivation , entrepreneurial strategy and business performance, the entrepreneurs tend who is more open and stronger in self-realization will have a better Business performance. The study of Xu Dong Chan (2008) on the relations of personality, entrepreneurial spirit and Business Performance, the results show entrepreneurial pull-type motivation has no significant effect on entrepreneurship non-economic performance; while entrepreneurship entrepreneurial push-type motivation has a significant negative impact on entrepreneurship non-economic performance. Based on the previous discussion, this study proposes the third hypothesis.

H3: hairdressing internal entrepreneur's motivation has a impact on the effect of the entrepreneur's personality on business performance, which means the interaction effect of the entrepreneur's personality and motivation has an effect on their business performance.

\section{Research Methods}

\subsection{The Research Framework}

This part is to review the related theories and literatures, this study will integrate the relevant factors on the performance in hairdressing chain services entrepreneurs "personality" and "entrepreneur's motivation", and the structure of this study is:

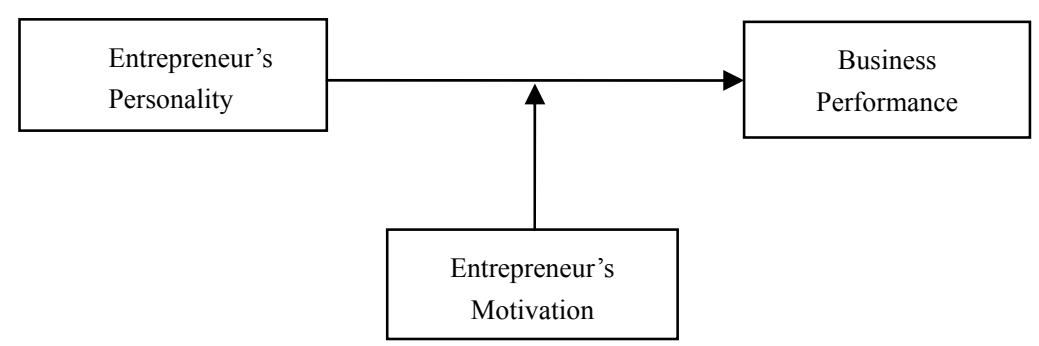

Figure 2. Research framework 


\subsection{Research Hypothesis}

According to the literature and research purposes of this study, the research hypotheses are as following.

H1: hairdressing internal entrepreneur's personality has a positive impact on business performance.

$\mathrm{H} 2$ : hairdressing internal entrepreneur's motivation has a positive impact on business performance.

H3: hairdressing internal entrepreneur's motivation has a impact on the effect of the entrepreneur's personality on business performance, which means the interaction effect of the entrepreneur's personality and motivation has an effect on their business performance.

\subsection{Data Analysis Methods}

In this study, Excel and SPSS software package are used for empirical analysis, based on the purpose and to test hypothesis, descriptive statistics analysis, reliability analysis, validity analysis, factor analysis, correlation analysis and hierarchical regression are used.

\subsection{The Basic Information Described in Statistical Analysis}

The main items of the questionnaire are for the basic descriptive statistics data analysis of the subjects, including the surveyors' sex, age, blood type, position, the age, marriage status, the education background when they start business, company establishing time, the number of employees when company was just founded, registered capital, the number of current employees.

\subsection{Reliability Analysis}

The questionnaire used Cronbach's $\alpha$ coefficient to measure its internal consistency, reliability which represents the consistency of the same or similar precursor, using the same particular technique to study and the degree of similarity obtained after repeated measurements, that is the consistence of measuring result.

Based on the correlation coefficient and analysis of variance, and after reviewing two hundred study reports about reliability, Wu Tongxiong (1990) recommended to use it as a reference standard for the level of credibility.

\subsection{Validity Analysis}

Validity is able to measure the characteristics and functions the research center wants, ie the correctness of a test. The content validity degree is used to examine the validity of the questionnaire in this study. Content validity refers to the appropriateness of measurement tool, if questionnaire covers all the content we want to discuss, and then it has excellent content validity. The questionnaire of this study is based on theories and many past similar questionnaires, and then modified object properties after collecting the opinions of the scholars, experts and stakeholders so that the measure tools used in this study are consistent with content validity requirements.

\subsection{Factor Analysis}

Factors analysis is an attempt to explain the relationship between a group of variable mode with a few factors to enrich data. In this study, the factor analysis is used to analyze the information collected from the questionnaire to see if the questions are suitable for the variables, and then the number of variables is confirmed, which constructs a certain representation and can be used as the foundation of a follow-up analytical framework.

\subsection{Correlation Analysis}

Correlation analysis is mainly used to measure the relevance between two random variables. In this study, we used Person correlation analysis to measure the variables of each dimension, to see if there is relevance in the variables of all the dimensions.

\subsection{Hierarchical Regression Analysis}

The hierarchical regression analysis is used to verify the research hypotheses. Here are the orders of hierarchical level: first, the independent variables; second, the moderating variable and the third, the interaction variables (measure the product of the independent variables and the disturbance variable).

According to the variance increment, we will know if each group of variables can effectively explain the relation between the entrepreneur's personality and business performance. In addition, about the problem of the interaction term leads a high collinearity to regression model will be solved by interaction term variables observed minus average in this study. Finally, when the moderating effect is significant, we can understand the direction of its regulation according to the chart of relevant variables.

\section{Research Results}

According to the purpose of this study and the research hypothesis, this study used SPSS statistic software for 
Window 12.0 to verify, and explain the results. We collected the information of effective questionnaire 150 copies, managing, analyzing and comparing the data, based on the results of data analysis, we will discuss the results and provide the conclusion and suggestion in the end of the study.

\subsection{Company Information Analysis}

According to the company's basic information, in accordance with the company qualification, the number of employees when corporate entrepreneurship founded, the current number of employees, registered capital, the results are shown in Table 1. On the distribution of the establishment of the company qualification, mainly focus on six years to 10 years, accounted for $36.1 \%$, followed by 3 to 5 years, accounted for $27.1 \%$. The number of employees when company founded, most is 5 to 10 people, which account for $48.4 \%$ of all scales. In the current number of employees, 5 to 10 people accounted for $47.7 \%$, on the whole, there is no big difference between the number of employees when company started and the company's current number. About registered capital, less than 30,000 Yuan accounted for $47.7 \%$, followed by 30,000 to 100,000 Yuan, accounted for $31.0 \%$.

\subsection{The Statistics Analysis of Dimensions}

\subsubsection{Personality Trait Data Analysis}

This section is the results of the descriptive statistics personality for various dimensions. We got the results by taking Likert Scale with 1 to 5 levels of the receptivity from low to high. The results are as below.

Most of the entrepreneurs agree with "I am more compassionate, kind, considerate, easily to be moved", "I am quite imaginative and curious, and I can accept new ideas, and take the initiative to try new experiences.", "I am quite self-discipline and self-improving, reliable, and trustworthy", etc., and they don't agree "I'm more conventional, stick to the conventional, not creative", "I like to criticize, argue, debate and complain", "I am more implicative, apathy, gentle and quiet" etc.

\subsubsection{Business Performance Data Analysis}

Business performance is divided into six items, respectively for business growth, employee turnover, market share, ROI, morale, and asset returns, Likert scale is adopted to get the results as following.

On the business performance, most of entrepreneurs agree with "morale" and "market share", etc., and don't agreed to the "business growth" and "return on investment", etc. In addition to the "satisfaction", most agree the ratio of "employee turnover after three years" is lower than the main competitor, etc., and less agree to "the business growth reaches to a desired goal after three years" and "the start-up" asset returns reaches to a desired goal after three years, etc.

About comprehensive important degree and degree of satisfaction, most agree "the employee turnover three years after" less than the main competitors and the morale is higher than the main competitor after three years, etc., and less agree to "the business growth reaches to a desired goal after three years", and the assets return reaches to a desired goal after three years.

\subsubsection{Entrepreneur's Motivation Data Analysis}

Entrepreneur's motivation is divided into seven dimensions, namely achievements, benefits, status, money, exempt from difficulties, liberty and imitate their predecessors, Likert scale was adopted, depending on the level from low to high degree $1-5$, the results are as following.

The main motivation for starting business is "I start to need more money. followed by "my business is able to apply technical into practice" and "I hope I can accept the challenge", thereby the success and money have important effect on entrepreneur's motivation. While "I want to create benefits for the birthplace", and "My business is to continue the family tradition" have least effect on entrepreneur's motivation.

\subsubsection{The Shareholding Ratio of Enterprises}

About the enterprise equity the founders have, the equity ratio is divided three items, below $30 \%$, below the $49 \%$ and more than $51 \%$.

The percentage of owning the store's equity less than $30 \%$ is 48.4 , the percentage of owning the store's equity less than $49 \%$ but more than $31 \%$ is 27.1 , the percentage of owning the store's equity more than $50 \%$ is 24.5 , overall, most owners have less than $30 \%$ of the equity.

\subsection{Reliability, Validity and Factor Analysis}

This section will use reliability analysis, validity analysis and factor analysis to analyze the questionnaire, to verify whether the questionnaire items have the property of verification. 


\subsubsection{The Reliability Analysis}

This questionnaire takes Cronbach's Alpha coefficient as reliability as measure standard to measure the consistency. Generally, Cronbach's Alpha coefficient value more than 0.7 indicates that the reliability is good. In this study, the personality construct reliability is 0.820 , and the reliability of performance importance, satisfaction with the performance, and entrepreneur's motivation is up to 0.9 , which meet the requirements Cronbach's Alpha coefficient, therefore the questionnaire has good reliability in this study.

\subsubsection{Factors Analysis}

In order to be clearer about the contribution of the factors, we analyzed the samples by factor analysis on three dimensions, including personality, entrepreneur's motivation and Business Performance, and then continue post study based on the results.

The value of KMO is up to 0.6 in each dimension, the results of Bartlett sphere verification show that this study does fit in factor analysis. In order to explain more clearly about the contributions of the factors, the principal component factor analysis method and varimax rotation are adopted to extract the main factors of dimensions and enrich data. Factors selection criteria is the commonality is greater than 0.5 , the eigenvalues are greater than 1 and cumulative contribution is more than $50 \%$, as the criteria of selecting the factors, and then name the factors based on the comprehensive question of common factors, the purpose is to more simply and easily explain the meaning of the various factors.

\subsection{Personality Trait}

\subsubsection{Personality Trait Scale}

$\mathrm{KMO}$ validation sampling adequacy quantity value is 0.83 , which is greater than 0.5 for factor analysis. And Bartlett's spherical validation test of $\mathrm{x}^{2}$ value $474.608(\mathrm{P}=0.000)$ is significant. There are common factors in the correlation matrix of groups, which is suitable for factor analysis.

The principal component analysis with varimax rotation was used for factor analysis, and took the variance whose eigenvalues greater than 1 and get the factor loading, eigenvalue and explained variance. There were 3 of the original 10 items of the scale did not meet the criteria of factor selection and were deleted, and 2 common factors were extracted in the remaining 7 items, its accumulation explanation to mutate the amount is $52.236 \%$, which are named the "agreeableness and extroversion" and "gender anxiety".

The dimensions of this study took the big five personality of Gosling et al. (2003) as questionnaire, but only two factors are extracted from personality, which probably because the questions were not enough and the subjects were not clear enough about the meaning of the questions due to the different expressions, another reason is the main subjects were chosen from the entrepreneurs who succeed, but lacking of the entrepreneurs who failed to fill in the questionnaire, this part needs to be discussed in further research.

\subsubsection{Entrepreneur's Motivation Scale}

KMO validation sampling adequacy quantity value is 0.902 , which is greater than 0.5 for factor analysis. And Bartlett's spherical validation test of $\mathrm{x}^{2}$ value $2580.865(\mathrm{P}=0.000)$ is significant. There are common factors in the correlation matrix of groups, which is suitable for factor analysis.

The principal component analysis with varimax rotation was used for factor analysis, and took the variance whose eigenvalues greater than 1 and get the factor loading, eigenvalue and explained variance. There were 12 of the original 28 items of the scale did not meet the criteria of factor selection and were deleted, and 2 common factors were extracted in the remaining 16 items, its accumulation explanation to mutate the amount is $50.356 \%$, which are named the "Wealth achievement" and "welfare free".

The dimensions of this study used the literature about entrepreneur's motivation of Dubini (1989) and Chen Weixin's thesis as the foundation of questionnaire, 7 factors about entrepreneur's motivations were extracted in these two studies, but only two factors are extracted in this study, the main reason is probably the changes of the economic society after nearly 17 years and different ethnic culture and values between eastern and western entrepreneurs, this part needs to be discussed in further research.

\subsubsection{Business Performance}

KMO validation sampling adequacy quantity value is 0.915 , which is greater than 0.5 for factor analysis. And Bartlett's spherical validation test of $\mathrm{x}^{2}$ value $715.397(\mathrm{P}=0.000)$ is significant. There are common factors in the correlation matrix of groups, which is suitable for factor analysis.

The original 6 items of the scale met the criteria of factor selection, and 1 common factors was extracted, its 
accumulation explanation to mutate the amount is $74.826 \%$, which is named the "Business Performance".

\subsection{Correlation Analysis}

Correlation analysis is to explore the relations of variables, if correlation coefficient is 0.4 above, which can be considered moderately related. The results are shown in table 1, and the details are as follows.

Table 1. Personality, entrepreneur's motivation, ratio of the share and business performance correlation analysis

\begin{tabular}{|c|c|c|c|c|c|}
\hline Agreeableness Extrovert & \multicolumn{2}{|c|}{ Gender Anxiety } & \multirow{2}{*}{$\frac{\text { Wealth Achievement }}{.749(* *)}$} & \multirow{2}{*}{$\begin{array}{r}\text { Welfare Free } \\
.360(* *)\end{array}$} & \multirow{2}{*}{$\frac{\text { Business Performance }}{.647(* *)}$} \\
\hline Agreeableness Extrovert & 1 & $.401(* *)$ & & & \\
\hline & & .000 & .000 & .000 & .000 \\
\hline \multirow[t]{2}{*}{ Gender Anxiety } & $.401(* *)$ & 1 & $.259(* *)$ & $.163(*)$ & $.281(* *)$ \\
\hline & .000 & & .001 & .042 & .000 \\
\hline \multirow[t]{2}{*}{ Wealth Achievement } & $.749(* *)$ & $.259(* *)$ & 1 & $.463(* *)$ & $.541(* *)$ \\
\hline & .000 & .001 & & .000 & .000 \\
\hline \multirow[t]{2}{*}{ Welfare Free } & $.360(* *)$ & $.163(*)$ & $.463(* *)$ & 1 & $.228(* *)$ \\
\hline & .000 & .042 & .000 & & .004 \\
\hline \multirow[t]{2}{*}{ Business Performance } & $.647(* *)$ & $.281(* *)$ & $.541(* *)$ & $.228(* *)$ & 1 \\
\hline & .000 & .000 & .000 & .004 & \\
\hline
\end{tabular}

** In a significant level of 0.01 (two-tailed), related significantly;

*In a significant level of 0.05 (two-tailed), related significantly.

\subsubsection{Personality}

Agreeableness and extroversion personality and business performance are at moderate levels of positive correlation when it is in significant level at $\mathrm{P}<0.01$.

The gender anxiety personality and Business performance are at low levels of positive correlation when it is in significant level at $\mathrm{P}<0.01$.

\subsubsection{Entrepreneur's motivation}

The achievement motivation of wealth related mo and Business performance are at moderate level of positive correlation when it is in significant level at $\mathrm{P}<0.01$.

The welfare free and Business performance are at low levels of positive correlation when it is in significant level at $\mathrm{P}<0.01$.

\subsection{Hierarchical Regression Analysis}

In order to test the hypothesis of this study, the main influence on Business performance traits, entrepreneur's motivation as well as the influence brought about by the interference, different prediction variables were put in each of these steps of the regression formulae, see Table 2.

Table 2. Hierarchical regression analysis

\begin{tabular}{|c|c|c|c|c|c|c|c|}
\hline \multirow{2}{*}{$\begin{array}{l}\text { Dependant variable } \\
\text { Independent variable }\end{array}$} & \multicolumn{2}{|c|}{ Model1 } & \multicolumn{2}{|c|}{ Model 2} & \multicolumn{2}{|l|}{ Model3 } & \multirow[b]{2}{*}{ VIF } \\
\hline & $\beta$ & $\mathrm{t}$ & $\beta$ & $\mathrm{t}$ & $\beta$ & $\mathrm{t}$ & \\
\hline Extraversion \&Agreeableness & $.259 * *$ & 3.138 & $.301 * *$ & 3.969 & $.285^{* *}$ & 3.575 & 1.027 \\
\hline Gender anxiety & .085 & 1.814 & .075 & .797 & .034 & .499 & 3.645 \\
\hline \multicolumn{8}{|l|}{ Extraneous variables } \\
\hline Wealth achievement & & & $.260^{* *}$ & 3.199 & $.259 * *$ & 3.138 & 3.001 \\
\hline Welfare free & & & $.150^{* *}$ & 2.529 & $.197 * *$ & 2.978 & 2.880 \\
\hline \multicolumn{8}{|l|}{ Interaction terms } \\
\hline \multicolumn{3}{|c|}{ Agreeableness extrovert*Wealth achievement } & & & \multicolumn{2}{|c|}{$3.921 * * 3.457$} & 2.607 \\
\hline \multicolumn{3}{|c|}{ Agreeableness extrovert*Welfare free } & & & .059 & .775 & 1.033 \\
\hline \multicolumn{3}{|c|}{ Gender anxiety $*$ Wealth achievement } & & & .091 & 1.806 & 4.235 \\
\hline \multicolumn{3}{|l|}{ Gender anxiety * Welfare free } & & & .068 & 1.086 & 3.213 \\
\hline \multicolumn{3}{|l|}{ R2 } & & & .050 & .273 & .341 \\
\hline \multicolumn{3}{|l|}{$\mathrm{F}$} & & & \multicolumn{3}{|c|}{$7.316 * * 14.815 * * 27.043$} \\
\hline
\end{tabular}




\begin{tabular}{llll}
\hline$\Delta \mathrm{R} 2$ & .041 & .259 & .323 \\
$\Delta \mathrm{F}$ & $7.316^{* *}$ & 44.333 & $13.593^{* *}$ \\
\hline
\end{tabular}

$* * \mathrm{~T}>2.54 ; \mathrm{P}<0.01$.

The first step is to put the independent variable of the two dimensions of entrepreneur personality in the regression formulae, the result shows that entrepreneurs' extroversion compatibility of personality can positively predict business performance $(=0.259, \mathrm{p}<0.01)$, which means the more agreeableness extrovert of personality entrepreneurs have, the better their business performance will be, the results support the hypothesis 1 of this study. The second step is to put the independent variable of the two dimensions of entrepreneur's motivation in the regression formulae, the results show that the wealth achievement $(=0.26, \mathrm{p}<0.26)$ and welfare free $(=$ $0.150, \mathrm{p}<0.01)$ can positively predict business performance. The above results can be explained as the more wealth and welfare free entrepreneurs have, the better business performance will be. The results support hypothesis 2. The third step is to put the independent variable of the hairdressing industry entrepreneurs personality of each dimensions and the interaction of entrepreneur's motivation in the regression formulae. In order to reduce the multiple collinearity problems brought by the interaction of items, we dealt with the interaction by "from the divided difference" treatment before it was put into the regression formulae. The results showed that the interaction of agreeableness extrovert and wealth achievement and the achievement of the regression coefficient has a positive significant influence $(=3.921, \mathrm{p}<0.01)$; which supports the third hypothesis as expected. The further study is to determine interference effect with interaction diagram drawn based on slope and intercept.

This study will focus on the directional test of interaction effect on entrepreneur's motivation. This study first put the value of interaction effect of agreeableness extrovert and variables, the achievement motive of wealth into the regression formulae, after organizing the data of regression formulae and to determine interference effect is positive or negative, see chart 3.

Whether the motivation level of Wealth achievement is high or low, it has a significantly positive effect on the relationship between agreeableness extrovert and business performance; in addition, when entrepreneurs' motivation level is high, it positive effect is more significant than their motivation level is low. When the entrepreneurs' level of achievement and agreeableness extrovert is high, they have better Business performance than those who don't; vice versa. The result supports the hypothesis 3 .

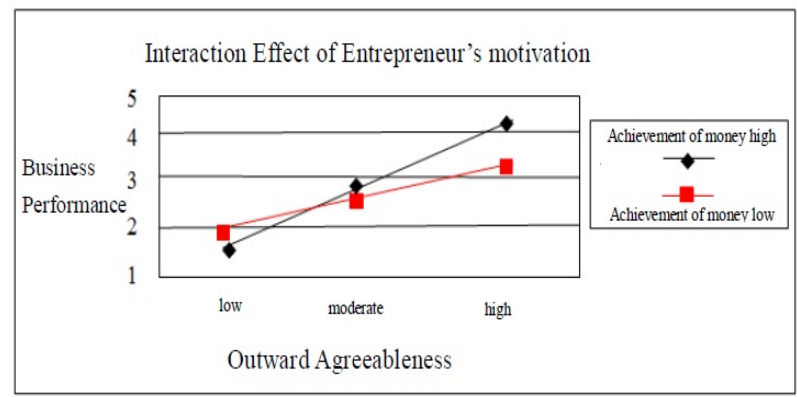

Figure 3. Interaction effect of entrepreneur's motivation on agreeableness extrovert and performance

\section{Conclusions and Suggestions}

\subsection{Conclusions}

Table 3. Results of hypothesis

\begin{tabular}{lll}
\hline Hypothesis & Result \\
\hline H1: & Hairdressing internal entrepreneur's personality has a positive impact on business performance. & support \\
H2: & Hairdressing internal entrepreneur's motivation has a positive impact on business performance. & support \\
\hline
\end{tabular}


H3: Hairdressing internal entrepreneur's motivation has a impact on the effect of the entrepreneur's personality support on business performance, which means the interaction effect of the entrepreneur's personality and motivation has an effect on their business performance.

\subsubsection{The Effect of Entrepreneur's Personality on Business Performance}

According to the result of research hypothesis 1, we found that the entrepreneur who has higher level of agreeableness extrovert has better performance.

\subsubsection{The Effect of Entrepreneur's Motivation on Business Performance}

According to the result of research hypothesis 2, we found that the entrepreneur who has higher level of motivation and welfare free has better Business Performance.

\subsubsection{The Effect of the Interaction of Entrepreneur's Personality and Motivation on the Business Performance}

According to the result of research hypothesis 3 , we found that the interaction of entrepreneur's personality and motivation has a positive effect on Business Performance.

\subsection{Study Limitations}

The dimensions of this study took the big five personality of Gosling et al. (2003) as questionnaire, but only two factors are extracted from personality, which probably because the questions were not enough and the subjects were not clear enough about the meaning of the questions due to the different expressions, another reason is the main subjects were chosen from the entrepreneurs who succeed in the business, but lacking of the entrepreneurs who failed the business to fill in the questionnaire, which needs to be discussed in further research.

\subsection{Study Contributions}

\subsubsection{Academic Contributions}

The issue of personality has been often discussed, but this issue has never been discussed in the field in Taiwan hairdressing industry. With the rapid development of hairdressing industry, we need to know more about the effect of entrepreneur's personality on the Business Performance, which is discussed in this study. It can help the entrepreneur to see how entrepreneur's personality affects their performance and help them to do best in their business.

\subsubsection{Practical Contributions}

This study helps the owner of company to know better about what type of personality is suitable for entrepreneurship, which is helpful for company to achieve their goals. According to this study, the entrepreneur who has higher level of agreeableness extrovert has better business performance, and the entrepreneur who has higher level of motivation and welfare free has better business performance.

\subsubsection{Suggestions to Entrepreneurs}

Most of Taiwan's entrepreneurs in hairdressing industry are not good at digital management, so they only try to expend their business based on their personal thoughts or experience. Through this study, the entrepreneur will know better that they should start their business when they embody the personality of agreeableness extrovert.

\subsection{Suggestions for Future Study}

The objects of the questionnaire were only the current entrepreneurs, however, lacking of the ones who used to be entrepreneurs but not anymore, more research about different group of objects are needed to complete this study. And most of current entrepreneurship research is directed at the entrepreneurial success of entrepreneurial behavior, few of them aimed at former entrepreneurs, which needs the follow-up study and then it can help us to have a more complete picture of Taiwan's hairdressing industry.

\section{References}

Amit, R., MacCrimmon, K. R., Zietsma, C., \& Oesch, J. M. (2001). Does money matter: Wealth attainment as the motive for initiating growth-orientted ventures. Journal of Business Venturing, 1(16), 119.

Collins, C. J., Hanges, P. J., \& Locks, E. A. (2004). The relationship of achievement motivation to entrepreneurial behavior: a ment-analysis. Human Performance, 17(1), 95-117.

Dai, W. T. (2000). The application of Big Five on human selection. 
Digman, J. M. (1990). Personality structure: Emergence of the five-factor model. Annual Review of Psychology, 41, 417-440.

Digman, J. M., \& Inouye, J. (1986). Further specification of the five robust factors of personality. Annual Review of Psychology, 50, 116-123.

Digman, J. M., \& Takemoto-Chock, N. K. (1981). Factors in the natural language of personality: Re-analysis, comparison \& interpretation of six major studies. Multivariate Behavioral Research, 16, 149-170.

Dubini, P. (1989). The Influence of Motivations \& Environment on Business Start-Ups: Some Hints for Public Policies. Journal of Business Venturing, 4(1), 11-26.

Fiske, D. W. (1949). Consistency of the Factorial Structures of Personality Ratings fron Different Source. Journal of Abnormal and Social Psychology, 44, 329-334.

Ghosh, B. C., \& Kwan, W. (1996). An analysis of Key success factors of SMEs: a comparative study of Singapore/Malaysia \& Australia/New Zealand. Unpublished doctoral dissertation, Nanyang Technological University.

Huang, B. D. (2006). The research on the relation of personality, motivation, strategy and performance. National Cheng Kung University.

Huang, G. Y. (2002). Research on the difference of service industry. Master thesis of Information society institute, Yuan Ze University.

John, O. P. (1990). The "big five"factor taxomony: Dimensions of personality in the natural language and in questionnaires. In Handbook of personality: Theory \& research. New York: Guilford Press.

Judge, T. A., Heller, D., \& Mount, M. K. (2002). Five-factor model of personality \& job satisfaction: A meta-analysis. Journal of Applied Psychology, 87(3), 530-541.

Jung, C. G., \& Long, C. E. (1917). Collected Papers on Analytical psychology (2nd ed.). London: Balliere Tindall \& Cox.

Lee, D. Y., \& Tsang, E .W. K (2001). The effects of entrepreneurial personality, background \& network activities on venture growth. Journal of Management Studies, 38(4), 583.

Li, C. G. (1997). Performance management and evaluation. Huatai cultural co., Ltd.

Li, N. (2009). Research on the Effect of Share Structure, Supervision Mechanism and Senior Managers' Salary on Business Performance. Business Management Department, National ILan University.

Lin, J. H. (2008). Effect of Beauty Salon Franchise Employees' Satisfaction and Organizational Commitment on Organizational Citizenship Behavior. Master Thesis of International Business Management Department, Dayeh University.

Lin, L. Y. (2009). Research on the Relevance of Female Entrepreneurs' Personality, Motivation and Business Performance (pp. 27-30). Business Management Department, Tamkang University.

Lu, S. Z., Yu, K. C., \& Qian, B. H. (1997). Organizational Behavior-Theory and Practical. Taibei, Wunan Publish.

Lu, Y. R. (2003). The effect of personality, entrepreneur strategy and programs on entrepreneur performance. Shi Chin University.

Luo, Z. M., Wang, J. R., \& Xu, X. J. (2008). The research of entrepreneur's personality on Business Performance: The mediating effect of relation network. Journal of Entrepreneurship Research, 57-88.

Norman, W. T. (1963). Toward an adequate taxonomy of personality attributes: Replicated factor structure. Journal of Abnormal and Social Psychology, 66, 74-583.

Peabody, D., \& Goldberg, L. R. (1989). Some Determinants of factor structures from personality-trait Descriptor. Journal of Personality and Social Psychology, 57(3), 552-567.

Peng, X. Q. (1993). Research on entrepreneurship in chain store. Business Department in Taiwan University.

Qiu, M. G. (2008). The effect of Taiwan Entrepreneurs' Personality, Motivation and Social Capital on Business Performance. Master thesis of Enterprise Management Department, Taibei University.

Schmit, M. J., Kihm, J. A., \& Chet, R. (2000). Development of a global measure of personality. Personnel Psychology, 53(1), 153-193. 
Tupes, E. C., \& Christal, R. E. (1961). Recurrent personality factors based on trait ratings. Journal of Personality, $60,225-251$.

Wang, Q. Q. (2003). Monitoring mechanism of establishing enterprise performance measurement indicators. Master thesis of Accounting Institute, National Chung Cheng University

Woodworth, R. S. (1991). Examination of emotional fitness for war. Psychological Bulletin, 15(1), 59-60. York: Guilford Press.

Xu, D. Z. (2008). Research on the Relevance of Entrepreneurs' Personality, Motivation and Business Performance. Master thesis of Management Department, National Cheng Kung University.

$\mathrm{Xu}, \mathrm{Y} . \mathrm{T}$. (2002). Mother and her daughter, The experiential world of religious man. Master thesis of ethnic relations and culture institute, National Dong Hua University

Yang, M. L., Huang, Y. J., \& Lai, Y. Z. (2009). Research on Entrepreneurs' Motivation,Entrepreneurial Direction and Business Performance. Journal of Entrepreneurship Research, 413, 5-81.

Zhou, H. L. (2003). Research on the relation of Big Five, sex role and transformational leadership. Master thesis of Shih Chien University.

\section{Copyrights}

Copyright for this article is retained by the author(s), with first publication rights granted to the journal.

This is an open-access article distributed under the terms and conditions of the Creative Commons Attribution license (http://creativecommons.org/licenses/by/3.0/). 